\title{
CONTRIBUIÇÓES PARA A HISTÓRIA DO ENSINO SUPERIOR: EGRESSOS DA FACULDADE DE DIREITO DE PELOTAS-RS/BRASIL E FACULDADE DE DIREITO DE COIMBRA/PORTUGAL
}

\author{
Valesca Brasil Costa* \\ Chanauana de Azevedo Canci Manfio**
}

\section{Resumo}

Este trabalho é dedicado a revisitar a memória de alunos egressos da Faculdade de Direito de Pelotas-RS/Brasil e da Faculdade de Direito de Coimbra/Portugal, tendo como recorte temporal o período compreendido entre as décadas de 1960 e 1970. Este recorte temporal se justifica, pois no Brasil se deu o Golpe Civil Militar (início da Ditadura Militar no Brasil) e em Portugal, se deu a Revolução dos Cravos (fim do Regime Salazarista em Portugal). Deste modo, este trabalho investigou a história da educação brasileira, bem como das duas instituições jurídicas, a partir da memória de seus egressos, cabendo destacar que ambas as instituições são representativas de uma cultura jurídica, de relevante significado no contexto de formação de bacharéis em Direito, tanto no Brasil como em Portugal.

Palavras-chave: Educação. Memória. História da educação. Revolução. Faculdade de Direito.

\section{INTRODUÇĀO}

Este trabalho é resultado de uma pesquisa de doutoramento, dedicada a revisitar a memória de alunos egressos destas duas instituições de ensino superior, de maneira a buscar reconstruir, através de narrativas memorialísticas, as trajetórias de luta desses alunos contra sistemas totalitários.

Cabe considerar como recorte temporal, o período compreendido entre as décadas de 1960 e 1970, de modo que este se justifica, pois no Brasil se deu o Golpe Civil Militar ${ }^{1}$ e em Portugal, se deu a Revolução dos Cravos ${ }^{2}$. A título de esclarecimento, descreve-se o Golpe Civil Militar como o Golpe de Estado no Brasil no ano de 1964, que culminou com o fim do regime democrático do país, dando início ao período de ditadura militar, que por sua vez, foi uma forma de governo comandada e controlada por militares, valendo-se de efetivo autoritarismo. Igualmente, elucida-se que a Revolução dos Cravos trata-se da Revolução de 25 de abril de 1974 ocorrida em Portugal, decorrente de um movimento político e social que resultou no fim do regime ditatorial, instaurando-se o sistema democrático.

Doutora em Educação pela UNISINOS. Professora do Programa de Pós-graduação em Educação - Mestrado em Educação da Universidade Regional Integrada do Alto Uruguai e das Missōes - URI Câmpus de Frederico Westphalen/RS. Membro do Grupo de Pesquisa em Educação da URI/FW. E-mail: <valescacosta@gmail.com>.

Mestranda do Programa de Pós-graduação em Educação - Mestrado em Educaçáo da Universidade Regional Integrada do Alto Uruguai e das Missôes - URI Câmpus de Frederico Westphalen/RS. Bolsista em regime de dedicação exclusiva da CAPES/FAPERGS. Integrante do Grupo de Pesquisa em Educação da URI/FW. E-mail: <chanauana_canci@hotmail.com>.

Instrumento: R. Est. Pesq. Educ., Juiz de Fora, v. 20, n. 1, jan./jun. 2018 
Com o fim do regime ditatorial deixa de vigorar o conhecido "regime salazarista", assim denominado em referência a Antônio de Oliveira Salazar, que ocupava a chefia do governo naquele período.

Assim, é interessante destacar que esta pesquisa apresenta significativa importância em vários aspectos, um deles é contribuir, não apenas para a história da educação, mas também para a história das instituições jurídicas, campo este em que são escassos os estudos. Além disto, contribui como fonte para estudos sobre as origens do ensino jurídico no Brasil, que tomam por influência direta o direito europeu, possibilitando observar possíveis fatores que contribuíram para a situação de grave crise que o ensino jurídico brasileiro atual enfrenta, com carência de pesquisa e currículos muitas vezes desatualizados, dentre outros problemas, que podem estar diretamente relacionados com as bases históricas da criação dos cursos de direito no Brasil.

Deste modo, este trabalho se propóe a investigar a história de duas instituiçóes jurídicas a partir da memória de seus egressos, e o importante papel que a educação teve como instrumento de empoderamento dos egressos destas Faculdades de Direito, que participaram em momentos históricos decisivos, tanto em Portugal quanto no Brasil, na luta contra regimes totalitários. Além disso, se observou também como a educação foi um instrumento decisivo para dinamizar as relaçóes sociais dentro da comunidade jurídica desses dois países.

É fundamental destacar que ambas as instituições de Direito estudadas são representativas de uma cultura jurídica, de relevante significado no contexto de formação de bacharéis em Direito, tanto no Brasil como em Portugal.

A história do Direito na Europa remete à sua origem, a Escola de Bolonha (Itália) - considerada a mais antiga da Europa, fundada em 1088 - e a origem do Direito romano sistematizado, com uma data aproximada entre 1055-1130. Entretanto, o ensino de Direito Romano de maneira sistematizada e codificada seria atribuído à data entre 1112-1125. Outra influência bolonhesa foi a elaboração do Decretum, uma codificação organizada pelo monge Graciano, Mestre em Teologia, tendo já se observado sua influência em Portugal quando constatado seu conteúdo em 1185 no testamento de D. Fernando Martins, então bispo da cidade do Porto, de maneira que se observa assim a interferência do direito romano e do direito canônico dentro de Portugal.

Desta maneira, se observa que Faculdade de Direito de Coimbra, em Portugal, representa a tradição de uma instituição que acumula mais de 500 anos. Além disso, a prática do ensino canônico, até os dias de hoje, reforça a influência que exerce a Igreja Católica em Portugal, diferenciando-se um pouco do contexto de institucionalização da Faculdade de Direito de Pelotas, cuja contribuição da maçonaria é significativa.

Quanto aos estudos de Direito, no Brasil, a "cultura do bacharel" advém dos tempos da colonização, quando jovens de famílias ricas se direcionavam até a Faculdade de Coimbra, em Portugal, para desempenharem seus estudos, regressando com conhecimento jurídico, gerando grande prestígio.

A instalação dos cursos de Direito no Brasil está intimamente relacionada com a história de Portugal e a consequente transferência, ou fuga, da família real portuguesa em 1808, quando Napoleão Bonaparte invadiu Portugal e a sede do poder metropolitano foi deslocada para o Brasil.

A necessidade de uma comunidade jurídica nacional no Brasil crescia, em especial, devido à independência do Brasil, em 7 de setembro de 1822, perante Portugal, fazendo surgir a necessidade de criação da própria comunidade jurídica brasileira, visto que, até então, grande parte era de bacharéis em Direito graduados em Coimbra. 
Assim, no decorrer deste trabalho, se estudará como os alunos egressos da Faculdade de Direito de Coimbra/Portugal, bem como os da Faculdade de Direito de Pelotas/Brasil destacaram-se em momentos de ebulição e transformação política em ambos os países. Suas trajetórias apontam caminhos para a compreensão dos processos históricos da educação em nível superior, sobretudo no que diz respeito ao campo jurídico, e ainda analisa a condição dos egressos dessas duas instituiçóes de ensino de Direito, figurando-os como trânsfugas, ou herdeiros, diante do cenário político contextualizado.

No que se refere à fundamentação teórica, este trabalho toma como base conceitos trabalhados nas obras de Pierre Bourdieu, dedicadas à educação, de maneira que a apropriaçáo desses conceitos possibilita considerar que, na maioria dos casos, se dá a "reprodução", isto é, aqueles que já detêm certo "capital cultural" apenas transmitem a seus "herdeiros" oportunidades e situaçóes que favorecem posiçôes de destaque dentro da sociedade. Dito de outra forma, se constata o que foi defendido pelo autor quando se faz referência ao verdadeiro papel do sistema educativo. Para melhor explicar o que Bourdieu entende por reprodução e sua relação com a educação, Bonnewitz (2003, p. 114) afirma que:

\footnotetext{
A escola, tomada no sentido de sistema educativo, parece entáo como um instrumento de realização deste ideal igualitário. Essa vontade que se tornou crença amplamente compartilhada, foi contestada por duas obras publicadas por P. Bourdieu e seus colaboradores: Le héritiers (1964), referente à universidade, e La reproduction (1970). O resultado desses estudos é conclusivo: a escola, longe de reduzir as desigualdades sociais, contribui para reproduzi-las.
}

Desta feita, se parte do pressuposto de que a educação, em grande parte, repete posições sociais já existentes na sociedade. Assim, a proposta deste trabalho se dá na análise das questôes empíricas da investigação, sob a perspectiva bourdiniana. Este estudo reconstruiu percursos de egressos da Faculdade de Direito de
Pelotas-RS, no Brasil, e da Faculdade de Direito de Coimbra, em Portugal, em períodos em que ambos os países passavam por regimes ditatoriais.

\section{A TRAJETÓRIA METODOLÓGICA DE INVESTIGAÇÁO DO OBJETO: HISTORICIDADE E MEMÓRIA}

Esta pesquisa tem como início uma abordagem dedicada à trajetória metodológica realizada nessa investigação, bem como a escolha teórica que sustenta a análise que dá corpo à escrita deste trabalho. Utilizase a expressão "pistas" no decorrer dessa pesquisa, constituindo-se um "olhar detetivesco", semelhante prática da área jurídica de reunir pistas ou argumentos que servissem para desenvolver a tese arguida. $O$ pesquisar e encontrar as pistas para escrita desse trabalho é uma tentativa de "ampliar as possibilidades investigativas":

\footnotetext{
As inovaçôes nos objetos de pesquisa e a emergência de novos conceitos, voltados para os domínios do cultural, influenciaram os historiadores a ampliar o seu olhar detetivesco sobre a história. Dessa forma, a análise sobre representação, imaginário, narrativa e sensibilidades inseriu-se na história, justamente, para ampliar as possibilidades de compreensão do passado (AMARAL; SILVEIRA, 2012, p. 169).
}

Com tal propósito, foram buscados documentos, objetos e pistas que permitiram reconstruir, partindo de documentos orais, a trajetória dos egressos da Faculdade Direito de Pelotas (UFPEL), Brasil, e da Faculdade de Direito de Coimbra, Portugal, entre as décadas de 1960 e1970, e a participação desses no cenário político correspondente, analisando suas condições de trânsfugas ou herdeiros.

O ponto de partida desta fase da pesquisa foi a extração de notícias que dessem conta do momento e das condições em que vivia a sociedade pelotense na década de 1960 e, mais especificamente, a comunidade jurídica 
pelotense, com pesquisas constantes e diárias junto à Bibliotheca Pública Pelotense (fundada em novembro de 1875 pelo jornalista Joaquim Dias, e com a colaboração de pessoas ilustres da cidade como João Simóes Lopes, também denominado Visconde da Graça), utilizando o jornal "Diário Popular" como uma das fontes de estudo. Isto porque, considerando os meios de comunicação da época, imprescindível foi a contribuição da imprensa para a elaboração de trabalhos em História.

Diante de um presente traçado por incertezas e indecisōes, recorre-se às memórias da história da educação, para apontar um caminho de compreensão. É necessário que o passado, por meio de suas experiências, aponte para uma racionalidade no tempo presente, que muitas vezes passa despercebida, se não analisada em uma contextualização histórica. Magalhães (1998, p. 14-15), evidencia a importância sumária do estudo do passado em matéria de educação:

Em matéria de educação, o estudo do passado
pode visar a descriçáo, a legitimação histórica e
manutenção do status quo, como pode constituir o
ponto de partida para a inovaçáo do conhecimento
científico e dos métodos e processos de ensino
[...]. A abordagem historiográfica revela-se das
mais fecundas quando se intenta a explicação
da complexidade educacional [...] e constitui
um saber-fazer investigativo e discursivo que se
ajusta à complexidade da acção e da racionalidade
educativas.

Dentre os fundamentos históricos da educação no Brasil, é mister salientar o desenvolvimento de trabalhos que envolvam a historicidade, pois os procedimentos característicos da escrita da história permitem o entendimento para além do que foi apresentado, dispensando maior atenção para outros fatores, como, por exemplo, para o reconhecimento e distinção das principais categorias históricas que serão abordadas.

É interessante destacar que podemos citar, ainda, os cuidados especiais com o tratamento dos documentos, das mais variadas formas, a serem empregados na pesquisa, ou até mesmo o reconhecimento dos instrumentos de trabalho do pesquisador, como arquivos, periódicos, jornais, bibliotecas, manuscritos. Nesse processo, torna-se fundamental a sensibilidade de uso e significância das palavras e termos, para que reflitam e possa reproduzir com o máximo possível de exatidão a informação e a compreensão exposta.

Em relação aos procedimentos adotados pelo pesquisador, nas palavras de Neves (2009, p. 26):

$$
\begin{aligned}
& \text { [...] possibilitam-nos a percepção de que um } \\
& \text { trabalho histórico se caracteriza não apenas } \\
& \text { pelas generalizaçóes universais, mais próximas } \\
& \text { do campo da Filosofia, mas pela minúcia do } \\
& \text { pormenor concreto; pela investigação empírica } \\
& \text { e documental, pela preocupação em relacionar a } \\
& \text { ordem de permanência e a ordem da transformaçáo, } \\
& \text { observando sempre o reconhecimento dos diferentes } \\
& \text { ritmos e tempos históricos. Por conseguinte, } \\
& \text { perante tantos desafios, é saudável termos cautela } \\
& \text { no exercício, no fazer da História da Educaçáo [...]. }
\end{aligned}
$$

A busca pela compreensão do fenômeno educativo diante do movimento histórico é o maior desafio que perpassa as pesquisas na atualidade, devendo primarse pelo científico-metodológico, sem que, no entanto, abra-se máo do contato com o passado. $\mathrm{O}$ caráter inter e transdisciplinar das temáticas envolventes à história da educação reforçam a complexidade e a exigência da caracterização de escrita e de leitura como uma constante reconstrução, sendo o pressuposto básico inerente a esse processo.

Assim, no que se refere à metodologia desenvolvida para trabalhar com as fontes, e neste caso especificamente com jornais na cidade de Pelotas, foram selecionados aqueles que compreendiam o período de proximidade do Golpe civil-militar de 1964, o que levou a recorrer ao ano de 1961, ou seja, o conhecido "pré-golpe".

Quanto ao tratamento dado à pesquisa com jornais, o foco foi na procura de notícias que falassem especificamente sobre a participação dos alunos das Faculdades de Direito de Pelotas e de Portugal em 
atividades relacionadas ao momento de movimentação política deste recorte temporal, em cada país. Fischer (2005), alerta quanto ao uso de fontes jornalísticas, quando se deve considerar que os jornais representam uma fonte envolvida em "jogos de poder”, passíveis de invenções, sendo uma representação construída do real vivenciado.

O jornal Diário Popular, que data há 120 anos na cidade de Pelotas, tem circulação diária, cabendo considerar que foram consultados jornais desde o início do ano de 1960, até o final de 1965, na busca por notícias que estivessem relacionadas com a Faculdade de Direito de Pelotas e com alunos ou membros desta faculdade. Ao passo que a metodologia de estudo em jornais ia sendo desenvolvida, se estabelecia uma reconstruçáo histórica da cidade de Pelotas e da comunidade jurídica.

Não limitada a este panorama local da cidade e da Faculdade Pelotense de Direito, a pesquisa também propõe um estudo global, dedicando-se à pesquisa da realidade social de Portugal, no período que foi base da Revolução dos Cravos (25 de abril de 1974), que derrubou o regime ditatorial Salazarista, e ainda a história da tradicional Faculdade de Direito de Coimbra.

Desta maneira, cabe observar que na segunda fase, efetivada em Portugal, além de se aprofundar o estudo bibliográfico, houve a pesquisa de campo feita na Faculdade de Direito de Coimbra, e em jornais na Biblioteca Municipal de Coimbra e na Biblioteca Pública da Cidade do Porto, sendo feito concomitantemente entrevistas com alunos egressos da Faculdade de Direito de Coimbra/Portugal que foram membros ativos na Revolução dos Cravos.

Assim, de modo semelhante se deu o processo de pesquisar em jornais no Brasil, deu-se também em Portugal, entretanto, aprofundando o recorte temporal na década de 1970, visto que esse foi o período de maior fragilidade da ditadura salazarista e que precedeu a "Revolução dos Cravos". Em Portugal, a pesquisa documental envolveu acesso a mais de um periódico, e também a investigação realizada nas Bibliotecas Municipal de Coimbra e Municipal Almeida Garret, da cidade do Porto.

Na biblioteca de Coimbra foi consultado o jornal "Diário de Coimbra", considerando o fato de ser o jornal da cidade em que estava instalada a Faculdade de Direito pesquisada em Portugal. O objetivo era identificar, nas narrativas jornalísticas, como os efeitos do cenário político de Portugal haviam repercutido na cidade de Coimbra.

Ainda sobre o jornal "Diário de Coimbra", cuja circulação é diária nesta cidade, foram consultadas ediçóes do início do ano de 1973 até o final do ano de 1974, isto porque, a intenção era observar o cenário político social de Coimbra e Portugal antes da Revolução dos Cravos de 1974, e a situação posterior. Para Coimbra, o critério de análise das notícias foi que seu conteúdo estivesse relacionado com a Faculdade de Direito de Coimbra e com alunos ou membros daquela faculdade.

Quando na cidade do Porto, a pesquisa em jornais foi realizada após concluir o estudo no jornal de Coimbra, dedicando-se a pesquisar o jornal de maior circulação em Portugal, que, na ocasião do recorte temporal pesquisado, seria o "Diário de Notícias", considerado o jornal de maior tiragem.

E da mesma forma como foi realizado com o jornal anterior em Coimbra, foram consultados jornais desde o início de 1973 até o final de 1974, buscando, como critério de pesquisa, notícias relacionadas com a Faculdade de Direito de Coimbra, uma vez que essa era a instituição de Direito pesquisada em Portugal, e informações da participação ou envolvimento de alunos ou membros dessa faculdade em atividades, naquele momento de transformação política.

Ainda no que se refere à consulta em jornais em Portugal, é fundamental destacar que a pesquisa teve uma peculiaridade observada já com certo olhar 
de desconfiança ainda no início da investigação em periódicos. Esse olhar de desconfiança se deu pelo fato de que, ao contrário das pesquisas feitas nos jornais em Pelotas nos quais era percebida a movimentação linear das ebulições políticas no Brasil que levaram ao consequente golpe civil-militar de 1964, em Portugal os jornais se mantiveram em um silêncio velado sobre notícias que dessem conta do momento crítico que a sociedade portuguesa se encontrava, sob o poder do ditador português Salazar. Nada mencionavam, e em especial pela crise decorrente das guerras contra a colônia africana, demonstravam uma forte censura, de maneira que só começaram as notícias sobre a efervescência na política portuguesa nos dias que sucederam a "Revolução dos Cravos”, ocorrida em 25 de abril de 1974.

Em ambos os jornais pesquisados para o estudo em Portugal, a investigação remeteu-se ao ano de 1973, ano antes do término da ditadura salazarista, com o propósito de compreender esse contexto de abertura política.

Da mesma maneira que em Pelotas, o foco era extrair assuntos que identificassem a participação de egressos da Faculdade de Direito de Coimbra no momento de efervescência política que culminou com o fim do regime salazarista, do entáo jurista Marcello Caetano, último Presidente do Conselho do Estado Novo.

Ao utilizar os documentos de fundo jornalístico, como argumenta Le Goff (2012), a narrativa é desconstruída para posteriormente ser reorganizada, selecionada e apresentada de outra maneira, para que seja possível cotejá-la com as questóes de pesquisa. Isso exige uma postura vigilante e disciplina para compreender os jogos de poder e o aspecto tendencioso do que era "permitido" noticiar sobre o cenário político, pois a prática da leitura de jornais agrega ao capital cultural como um instrumento de poder. Nas palavras de Le Goff (2012, p. 548):

O documento é um monumento. Resulta do esforço das sociedades históricas para impor ao futuro - voluntária ou involuntariamente determinada imagem de própria. Produto de um centro de poder, de uma senhoria quase eclesiástica, social, jurídica, política, cultural, mas, sobretudo, enquanto instrumento de poder.

Como a metodologia usada para elaborar este trabalho foi construída entrecruzando fontes, não se poderia deixar de considerar o quanto foi "alinhavada" também pela história oral e memória, através de entrevistas feitas com alguns alunos egressos destas instituiçôes jurídicas. Assim, no próximo momento, esse sentido atribuído ao documento é detalhado quando as memórias, traduzidas e organizadas, são tratadas como documento para reconstrução de trajetórias dos egressos das Faculdades de Direito de Pelotas/Brasil, e de Coimbra/Portugal, no exercício de aproximação com os conceitos buordinianos, possibilitando compreender a condição de herdeiros e/ou de trânsfugas e sua inserção no meio jurídico, político e social.

\section{A ReVisitação da MEMÓria E A IMPRESSÃO DE LEMBRANÇAS}

Quando se trata de história oral, trabalha-se diretamente com uma noção de memória, pois de nada éa narrativa oral sem o sustento dessa, sendo imprescindível obter a clareza de que aquele que conta, que revisita sua memória, está de certa maneira impregnada pelos fatos mais atuais de sua vida, de seu cotidiano. Isso remete à necessidade de tomar determinados cuidados e fazer, sempre que possível, uma leitura para além daquilo que foi narrado.

A temática da memória foi, inicialmente, campo dos poetas e, a partir do século V a.C., dos historiadores e dos filósofos gregos. Naquela sociedade de fundamento mito-poético, o aedo desempenhava esse papel. Era quem, através das musas inspiradoras, resgatava a memória e a sua importância. A memória era sacralizada. A palavra poética enunciada construía 
verdades dentro da dimensão do tempo mítico, diferenciando-se do tempo cronológico (FÉLIX, 1998).

A temática da memória é preocupação que remonta aos gregos, Sócrates foi o primeiro a comparar a obra da memória no indivíduo a um bloco de cera, na qual seriam impressas as lembranças. Já Platão e Aristóteles, se preocuparam com a relação entre lembrança e imagem no processo de evocação da memória, como enfatiza Bosi:

\footnotetext{
Não há evocação sem uma inteligência do presente, um homem náo sabe o que ele é se não for capaz de sair das determinaçóes atuais. Aturada reflexão pode preceder e acompanhar a evocação. Uma lembrança é diamante bruto que precisa ser lapidado pelo espírito. Sem o trabalho de reflexão e da localização, seria uma imagem fundida. O sentimento também precisa acompanhá-la para que ela não seja uma repetição do estado antigo, mas uma reaparição (BOSI, 1994, p. 81).
}

A memória continuará sendo ponto de união entre passado e presente. Ela permite fazer este intercâmbio. A evocaçáo da memória é sempre influenciada pelas experiências acumuladas dos sujeitos, portanto, passíveis de esquecimentos e invençóes, como assinalam Souza e Grazziotin (2012).

Bosi (1994, p. 53) ainda acrescenta que a "lembrança é a sobrevivência do passado. O passado, conservandose no espírito de cada ser humano, aflora à consciência na forma de imagens-lembranças". É que cada sujeito busca em suas memórias os fragmentos e vai aos poucos juntando pedaços daquelas memórias que permitem chegar ao mais próximo do que era a realidade rememorada.

Assim, o argumento anterior recebe respaldo e complemento quando Amado (1995) considera que, ao trazer o passado até o presente, há a sua recriação à luz do presente, ao mesmo tempo em que é projetado no futuro. Ao revisitar o passado os sujeitos dessa pesquisa trouxeram elementos fundamentais para a compreensão de suas origens, mostrando seus percursos até tornarem-se o que são, atuantes ou não, no contexto social em que vivem.
No século XX, a memória passou a ser importante objeto de reflexão nas ciências humanas. A problemática multifacetada que a análise das memórias individuais e coletivas envolve está associada, em larga escala, ao nome de dois pesquisadores que se constituíram em matrizes e referências para os estudos que têm se desenvolvido na área.

Pollack (1989), argumenta que nem tudo fica na memória, nem tudo é possível ser captado e armazenado na memória; a memória é seletiva. $\mathrm{Na}$ memória são armazenados, embora muitas vezes de maneira distorcida, lembranças, pessoas e sentimentos que ajudaram a compor aquela cena que ficou registrada na mente de maneira pretensamente inalterada enquanto evocação do passado.

Portanto, a história da educação parte do princípio de que uma determinada pesquisa deve considerar os diversos lugares e ambientes nos quais está ou esteve inserida em dado período de tempo, compreendendo a distinção temporal e a organização pessoal e social de cada sujeito envolvido. Colabora para esse entendimento Melo (2013, p. 17), em que cita Le Goff e Bora (1988), afirmando que:

\footnotetext{
Essa constatação permite ampliar os horizontes da pesquisa em história da educação, indo ao encontro da diversidade de problemas, abordagens e objetos, ressaltados por Le Goff e Nora (1988), tornando o campo da pesquisa em história da educação rico e variado. Considera os sujeitos envolvidos nos diversos processos de aprendizagem em tempos e espaços diversos e socialmente vivenciados o que acarreta as mais variadas fontes e interpretaçóes, e as mais variadas abordagens metodológicas.
}

Assim, a escrita deste trabalho revisita as memórias de alunos egressos da Faculdade de Direito de Pelotas e de egressos da Faculdade de Direito de Coimbra, ou seja, mantém viva a memória daqueles que fizeram a sua história e a história dessas instituiçóes, no sentido de conhecer, reconstruir e compreender a condição coadjuvante desses egressos, e seu envolvimento diante 
da situação política e social entre os anos 1960 e 1970, nos respectivos países estudados.

No momento da entrevista, há entre entrevistado e entrevistador certa cumplicidade, pois as memórias dos entrevistados serão de certa maneira despidas. $\mathrm{O}$ papel do pesquisador não é apenas procurar expor as memórias do entrevistado, mas deve ir além; precisa ser solidário naquele momento que, para muitos, não tem muita importância, contudo, para quem trabalha com história oral pode ser um momento fundamental.

Prosseguindo na pesquisa, é chegado o momento de aprofundar a questão bibliográfica no que tange às obras do autor Pierre Bourdieu, dedicado mais especificamente sobre questóes que envolvem a Educação, auxiliando na compreensão de alguns conceitos e ideias que contribuíram para a análise do material empírico.

Destaca-se, assim, que os conceitos de Bourdieu estão intimamente ligados e relacionados na dinâmica social não só da educação, mas em especial no espaço das instituições jurídicas, e se entende que o capital econômico é constituído pelos diferentes fatores de produção (terra, fábricas, trabalho) e pelo conjunto de bens econômicos: renda, patrimônio, bens materiais (BONNEWITZ, 2003).

Esse conceito mantém relação direta com o conceito de Capital Cultural, que corresponde ao conjunto das qualificaçóes intelectuais produzidas pelo sistema escolar ou transmitidas pela família (BONNEWITZ, 2003), isto porque manter o capital cultural está intimamente relacionado em deter o capital econômico, de maneira que, na análise dos demais conceitos que amparam este trabalho, nos depararemos com a figura justamente do filho daquele que detém o econômico e logo terá o acesso garantido ao cultural, apenas perpetuando a reprodução social e evitando a mobilidade e circulação de indivíduos entre as classes sociais.

Dessa perspectiva, o herdeiro, ou seja, aquele que recebe o Capital Cultural, Bourdieu caracteriza como o produto da ação contínua dos fatores que definem a posição nas diferentes classes em relação ao sistema escolar, a saber, o capital cultural e o ethos da classe, e por outro lado, esses fatores se convertem e se acumulam, em cada uma das fases da carreira escolar, numa constelação particular de fatores de retransmissão (BOURDIEU; PASSERON, 2009). Outro conceito fundamental foi o de Trânsfuga, entendido como pessoa que nasceu num meio social e que em sua vida adulta vive em outro meio social. $\mathrm{O}$ autor também considera o sistema escolar como um dos espaços responsáveis pela mobilidade social dos trânsfugas.

Quanto ao conceito de habitus, tomado como noção constituída de várias propriedades, esse adquire um sentido histórico, produto de uma ação histórica individual e coletiva, bem como, de uma educação associada a determinado meio. Esse sentido individual e coletivo do conceito, para a história, é a associação como categorias de pensamentos, as categorias de juízos, esquemas de percepçáo e sistemas de valores incorporados às estruturas sociais.

O conceito de campo, segundo a visão de Bourdieu, é utilizado na pesquisa desenvolvida como campo jurídico, pois se trata de um estudo que aborda, em seu conteúdo, uma realidade ligada às trajetórias de egressos das faculdades de Direito. O campo jurídico

é o lugar de concorrência pelo monopólio do direito de dizer o Direito [...] na qual se defrontam agentes investidos de competência ao mesmo tempo social a técnica que consiste essencialmente na capacidade reconhecida de interpretar (de maneira mais ou menos livre ou autorizada) um corpus de textos que consagram uma visão legítima, justa, do mundo social (BOURDIEU, 1989, p. 212).

Cabe observar, que um dos textos que mais contribuíram para a escrita deste trabalho, foi justamente quando o próprio Bourdieu se dedicou a falar sobre o campo jurídico. Em seu livro intitulado O poder simbólico, o autor dedica o capítulo VIII a 
estudar a sociologia do campo jurídico. $\mathrm{Na}$ discussão, o autor migra da filosofia para a sociologia e caracteriza as práticas e os jogos de poder próprios deste campo, afirmando que:

A ciência jurídica tal como a concebem os juristas e, sobretudo, os historiadores do direito, que identificam a história do direito com a história do desenvolvimento interno dos seus conceitos e dos seus métodos, apreende o direito como um sistema fechado e autônomo, cujo desenvolvimento só pode ser compreendido segundo a sua dinâmica interna (BOURDIEU, 1989, p. 209).

A partir do modo como se utilizou os conceitos bourdinianos em relação com a perspectiva da história cultural, foi possível reconstruir as trajetórias dos egressos que, ao revisitar as memórias de seu tempo acadêmico nessas duas instituições de ensino jurídico, trouxeram elementos para se conhecer e compreender como a condição de herdeiro ou trânsfuga conduziu as escolhas no âmbito social e cultural.

Cabe destacar que o trabalho de pesquisa começou a tomar forma à medida que, como considerado anteriormente, a sociologia de Pierre Bourdieu começava a fazer a leitura da dinâmica social que se dava nestas duas localidades, Pelotas/Brasil e Coimbra/Portugal, e de suas respectivas comunidades jurídica.

Assim, para embasar este estudo, a pesquisa foi além da revisão bibliográfica das obras de Pierre Bourdieu, aprofundando-se o estudo sobre a situação social do Brasil, e mais especificamente de Pelotas, no período da Ditadura Militar de 1964. Ainda sobre a centenária Faculdade de Direito de Pelotas, também conhecida como "Casa de Bruno Lima", percebeu-se desde os primeiros momentos de pesquisa a forte relaçáo que a cidade de Pelotas tem com a cultura e a educação e, em especial, com a instalaçáo de instituiçóes de grande vulto no ensino superior, como é a casa da Faculdade de Direito de Pelotas. Da mesma maneira se deu quando o estudo focou na tradicional Faculdade de Direito de Coimbra/Portugal, que além de ser referência no estudo jurídico europeu, foi também berço intelectual de muitos que resistiram ao regime totalitário de Salazar.

\section{Consideraçóes Finais}

Ao concluir este trabalho, se observa que a contribuição mais expressiva desta pesquisa é a certeza de que este estudo é o começo de um grande processo, que é o de revisitar a memória destes dois grupos de alunos egressos dos cursos de Direito, um grupo da centenária Faculdade de Direito de Pelotas, no Brasil, e o outro grupo da tradicional e histórica Faculdade de Direito de Coimbra, em Portugal. Isso se deve ao fato de a pesquisa não estar esgotada em si mesma, visto que não se exploroucompletamente a bagagem histórica destas duas instituiçóes, e da participação ativa de seus estudantes no processo de democratização nestes dois países.

Importa dizer que as instituiçóes pesquisadas representam relevantes significados no contexto de formação de bacharéis em Direito, tanto no Brasil como em Portugal. A análise das entrevistas, que por sua vez permitiram revisitar a memória dos alunos egressos destas duas instituiçóes e a análise dos documentos captados na pesquisa de campo, viabilizou a percepção do quanto foi ativa a participaçáo de alguns alunos, egressos da Faculdade de Direito de Pelotas/Brasil e da Faculdade de Direito de Coimbra/Portugal, na busca pelo fim dos regimes ditatoriais vigentes no período referido, nos dois países estudados, Brasil e Portugal.

Com isso, este trabalho observou que a sociedade sistematiza, institucionaliza e organiza as dinâmicas sociais e o pertencimento a determinado grupo detentor de "capital econômico" e de "capital cultural", que é um dos instrumentos que favorece o domínio neste jogo social. Nesse sentido, o campo do Direito, como criador de regras sociais, agrega "capital cultural" para os chamados "herdeiros", que pelo acesso ao campo jurídico permanecem como detentores do poder, 
garantindo para a elite de uma sociedade capitalista sua estabilidade no processo de dominaçáo.

Entretanto, na contramão dessa lógica, emergem sujeitos que mesmo não sendo detentores de "capital econômico" e/ou "capital cultural", fazem do conhecimento adquirido no campo do Direito um instrumento para dominar as regras desse espaço, e se consolidam como profissionais de destaque na comunidade jurídica, constituindo-se assim em "trânsfugas".

Assim, os sujeitos cujas memórias foram revisitadas, tornaram os conhecimentos adquiridos nessas instituições de ensino superior, em alguns casos, um instrumento na luta pela justiça, buscando derrubar regimes totalitários e outros. Além disso, viram a possibilidade de ascensão profissional e social, mostrando que mesmo em determinados casos a educação possui um papel de destaque na possibilidade de mobilidade do sujeito.

Contributions to THE history OF HIGHER EDUCATION: STUDENTS WHO GRADUATED FROM LAW SCHOOL IN Pelotas-RS/Brazil and the LaW School in CoImbra/Portugal

\section{Abstract}

This work aims to revisit the memory of students who graduated from Law School in the municipality of Pelotas, Rio Grande do Sul State, Brazil and from Law School of Coimbra University, Portugal. It describes the period that ranges between 1960s and 1970s, because of the civil-military coup in Brazil (the beginning of Military Dictatorship) and Carnation Revolution in Portugal (the end of Salazar's Dictatorship). This work aimed to investigate the history of Brazilian education, as well as the two law institutions from the memory of their graduate students, emphasizing that both institutions are representative of a legal culture of relevant meaning in the training context of bachelors of Law, both in Brazil and Portugal.

Keywords: Education. Memory. History of Education. Revolution. Law School.

\section{LAS CONTRIBUCIONES A LA HISTORIA DE LA EDUCACIÓN SUPERIOR: LOS GRADUADOS DE LA FACULTAD DE derecho de Pelotas / Brasil y la facultad de Derecho de Coimbra/ Portugal}

\section{Resumen}

Este trabajo está dedicado a revisar la memoria de antiguos alumnos de la Facultad de Derecho de Pelotas / Brasil y la Facultad de Derecho de Coimbra/Portugal, con el marco de tiempo del período entre 1960 y 1970 . Este marco de tiempo es por lo tanto, justificado en Brasil donde se observó el Golpe Civil Militar (inicio de la dictadura militar en Brasil) y en Portugal donde se dio la revolución de los claveles (fin del régimen de Salazar en Portugal). De este modo, este trabajo investigó la historia de la educación brasileña, así como de las dos instituciones jurídicas, a partir de la memoria de sus egresados, cabiendo destacar que ambas instituciones son representativas de una cultura jurídica, de relevante significado en el contexto de la formación de bachilleres en derecho, tanto en Brasil como en Portugal.

Palabras clave: Educación. Memoria. Historia de la educación. Revolución. Facultad de Derecho. 


\section{Notas}

Golpe de Estado no Brasil no ano de 1964, que culminou com o fim do regime democrático do país, dando início ao período de ditadura militar, que por sua vez, foi uma forma de governo comandada e controlada por militares, valendo-se de efetivo autoritarismo.

Revoluçấo de 25 de abril de 1974 ocorrida em Portugal, decorrente de um movimento político e social que resultou no fim do regime ditatorial, instaurando-se o sistema democrático. Com o fim do regime ditatorial deixa de vigorar o conhecido "regime salazarista", assim denominado em referência a Antônio de Oliveira Salazar, que ocupava a chefia do governo naquele período.

\section{REFERÊNCIAS}

ALVES, Luís Alberto Marques. História da educação: uma introdução. Porto: Faculdade de Letras da Universidade do Porto, 2012. Biblioteca Digital. Disponível em: <http://ler. letras.up.pt/uploads/ficheiros/10021.pdf>. Acesso em: 16 nov. 2017.

AMADO, Janaina. O grande mentiroso: tradição, veracidade e imaginação em História Oral. História, Sáo Paulo, n. 14, 1995.

FERREIRA, Marieta de Moraes (Coord.). Usos e abusos da história oral. Rio de Janeiro: Fundação Getúlio Vargas, 1998.

AMARAL, Giana Lange do; SILVEIRA, Josiane Alves da. Os bastidores de uma pesquisa em história da educação: a Faculdade Católica de Filosofia de Rio Grande/RS. Conjectura, Caxias do Sul, v. 17, n. 2, 25-35, maio/ago. 2012.

BONNEWITZ, Patrice. Primeiras liçöes sobre a sociologia de P. Bourdieu. Petrópolis, RJ: Vozes, 2003.

BOSI, Ecléa. Memória e sociedade: lembrança de velhos. São Paulo: Companhia das Letras, 1994.

BOURDIEU, Pierre. A dominação masculina. Rio de Janeiro: Bertrand Brasil, 1999.

. Homo academicus. Tradução de Ione Ribeiro Valle, Nilton Valle. 2. ed. Florianópolis: UFSC, 2013.

O diploma e o cargo: relaçóes entre sistema de produção e o sistema de reprodução. In: NOGUEIRA, M. A.; CATANI, A. M. Pierre Bourdieu, escritos de educação. 12. ed. Rio de Janeiro: Vozes, 2011. p. 127-144.

O poder simbólico. Rio de Janeiro: Bertrand Brasil, 1989.
O poder simbólico. Tradução de Fernando Tomaz.

2. ed. Rio de Janeiro: Bertrand Brasil, 1998.

Os três estados do capital cultural. In: NOGUEIRA, Afrânio Mendes; CATANI, Maria Alice. Pierre Bourdieu, escritos de educação. 12. ed. Rio de Janeiro: Vozes, 2011. p. 72-79.

. CHARTIER, Roger. O sociólogo e o historiador. Tradução de Guilherme João de Freitas Teixeira, com colaboração de Jaime A. Clasen. Belo Horizonte: Autêntica, 2011.

. PASSERON, Jean-Claude. A reprodução: elementos de uma teoria do sistema de ensino. Tradução de Reynaldo Bairão, revisão de Pedro Benjamin Garcia e Ana Maria Beta. 2. ed. Petrópolis, RJ: Vozes, 2009.

Los herederos: los estudiantes y la cultura. 2. ed. Buenos Aires: Siglo XXI, 2009.

COSTA, Valesca Brasil. A presença feminina na Faculdade de Direito de Pelotas/RS. 2009. 88 p. Dissertaçáo (Mestrado em Educação) - Faculdade de Educação, Universidade Federal de Pelotas, Pelotas, RS, 2009.

- Memórias de egressos das Faculdades de Direito de Pelotas/Brasil e Coimbral Portugal (1960-1970). 2014. 163 p. Tese (Doutorado em Educação) - Faculdade de Educação, Universidade do Vale do Rio dos Sinos, São Leopoldo, RS, 2014.

CUNHA, Maria Isabel da. No tempo em que o telefone era preto e a geladeira branca: a escola, a vida e as aprendizagens. In: FISCHER, Luciane Sgarbi Santos. Tempos de escola: memórias. São Leopoldo: Oikos; Brasília: Liber Livro, 2011, v. II. p. 95-106.

FÉLIX, Loiva Otero. História e memória: uma problemática de pesquisa. Passo Fundo: Universitária, 1998.

FISCHER, Beatriz Terezinha Daudt (Org.). Tempos de escola: memórias. São Leopoldo: Oikos, v. II, 2011.

Professoras: histórias e discursos de um passado presente. Pelotas: Seiva, 2005.

GONÇALVES, Nadia Gaioffato; GONÇALVES, Sandro. A. Pierre Bourdieu: educação para além da reprodução. 2. ed. Petrópolis/RJ: Vozes, 2011. (Coleção Educação e Conhecimento).

GRAZZIOTIN, Luciane Sgarbi Santos. Memórias recompondo tempos e espaços da educação: Bom Jesus/RS 
(1913-1963). 2008. 2 v. Tese (Doutorado em Educação) Faculdade de Educação, Pontifícia Universidade Católica do Rio Grande do Sul, Porto Alegre, 2008.

. ALMEIDA; Dóris Bittencourt. Romagem do tempo e recantos da memória: reflexóes metodológicas sobre história oral. São Leopoldo: Oikos, 2012.

HALBWACHS, Maurice. A memória coletiva. São Paulo: Vértice; Revista dos Tribunais, 1990.

HUNT, Lynn. A nova história cultural. São Paulo: Martins Fontes, 1992.

LE GOFF, Jacques. História e memória. Tradução de Bernardo Leitão [et al.]. 6. ed. Campinas, SP: UNICAMP, 2012.

MAGALHÃES, Justino. (Org.). Fazer e ensinar história da educação. Braga: CEEP/IEP - Universidade do Minho, 1998.

POLLAK, Michael. Memória, esquecimento, silêncio. Estudos históricos, Rio de Janeiro, v. 2, n. 3, 1989.

MELO, Francisco Egberto de. Por uma história política e cultural da educação: métodos, fontes e conceitos. In: RODRIGUES, Rui Martinho; LIMA, Jeimes Mazza Correia.; MARQUES, Janote Pires. (Org.). História, memória e educação. Fortaleza: EDUECE, 2013. p. 13-35.

NEVES, Fátima Maria Neves. A história da educação no Brasil: a trajetória de um campo de ensino e de pesquisa. In: ROSSI, Ednéia Regina; RODRIGUES, Elaine Rodrigues; NEVES, Fátima Maria Neves (Org.). Fundamentos históricos da educação no Brasil. 2. ed. rev. e ampl. Maringá: Eduem, 2009. p. 13-30.

SOUZA, José Edimar de; GRAZZIOTIN, Luciane S. Santos. Memórias evocadas: imagens recompondo as aulas isoladas em Novo Hamburgo/RS (1913 a 1952). Aedos: Revista do Corpo Discente do Programa de Pós-Graduação em História da UFRGS (Online), v. 4, p. 652- 674, 2012.

VILLAR, Waleska Ribeiro. A casa de Bruno Lima: uma face da história da Faculdade de Direito de Pelotas (19181965). 2004. 114 p. Dissertação (Mestrado em Educação) Universidade Federal de Pelotas, Pelotas, RS, 2004.

Enviado em 23 de janeiro de 2018

Aprovado em 20 de março de 2018 